\title{
Indústria, Desenvolvimento e Sustentabilidade: um Olhar Sobre a Questão dos Selos Ambientais.
}

Em tempos atuais, a interação entre a sociedade e o espaço ambiental está ganhando novas formatações, novas dimensões, e a concepção de desenvolvimento sustentável vem passando a se configurar nas discussões dos espaços industriais brasileiro. Que as indústrias são poluidoras em potencial, isso não se discute. Não existe meio de produção que não gere algum tipo de resíduos, sendo assim, é necessário estabelecer regras que visem à preservação ambiental à ecoeficiência .

A ABETRE (2003) aponta que o controle dos resíduos industriais depende ainda: de políticas públicas em relação à geração de resíduos industriais ou ao impacto ambiental; da pressão do mercado e da opinião pública sobre o desempenho ambiental do setor produtivo, fato que no Brasil está se realizando. Sendo assim, com as fortes pressões da sociedade, as empresas passaram a ter que apresentar novas alternativas, dentre elas, estabelecer suas políticas internas em função do atendimento à política ambiental. Haja vista que diante da consciência ambiental que a sociedade vem assumindo, as questões que tangem à sustentabilidade do planeta não só passam a ser valorizadas, como também passam a definir como diferenciais competitivos e até mesmo como condição de permanência no mercado. Fato é que, ainda que de forma muito lenta, já está se tornando possível identificar uma nova classe de consumidores que estão caminhando rumo a uma nova consciência social, cultural, política e ambiental, estes consumidores estão criando novos paradigmas, dentre eles, o do desenvolvimento sustentável e por essa razão, de certa forma, surgem como sociedade de controle, a cada dia, estão surgindo os cognominados consumidores verdes. Esses consumidores portam-se mais atentos às ações conservacionistas ambientais, adotadas pelas empresas, buscam produtos que foram elaborados com a concepção da menor degradação ambiental, do reaproveitamento, do não desperdício, procuram conhecer as políticas ambientais e as ações socioambientais, efetivamente desenvolvidas pelas empresas, para Layrargues (2000, p. 85) apud Pereira \& Guimarães(2009), o consumidor verde é:

[...] alguém que faz suas escolhas de compra, levando em consideração não somente qualidade e preço, mas o fato de ser ambientalmente correto, ou seja, para este consumidor o produto não pode ser prejudicial ao ambiente em nenhuma etapa do seu ciclo de vida, pois se acredita que o simples ato da compra determina uma atitude de depredação ou preservação. Assim, transfere-se o ônus da responsabilidade ambiental também para a sociedade.

O consumidor verde é o indivíduo que se propõe a conhecer não só o que consome, mas também como o bem a ser consumido fora produzido, tempo de vida útil do produto e reintegração desse produto ao meio ambiente e, até mesmo, as reais necessidades ou não da compra de um novo produto. São consumidores que antes de simplesmente comprar, observam a conduta da empresa e as certificações do produto e da empresa. Porém, para esses consumidores, ainda existem muitas barreiras a serem transpassadas, suscitam muitas dúvidas quanto à reputação e qualidade dos produtos e serviços, tidos como ambientalmente corretos. Os critérios que caracterizam os produtos não são claros, poucas são as informações, no que tange às questões ambientais e ainda aparece um elemento complicador, algumas empresas usam apelos, fazem marketing ambiental para produtos que na realidade não resguardam as características de qualidade e responsabilidade conservacionista ambiental.

Sendo assim, as empresas precisam fiarem-se em algo que estabeleça os critérios, as exigências, proponham a diferenciação e a fácil identificação dos produtos por parte 
dos consumidores. Nesse contexto, como estabelecedores de uma identidade ambiental para os produtos, surgem os selos ambientais, que são uma forma de atestados de garantia de que o produto foi processado e passou por critérios estabelecidos em normas nacionais e internacionais e que, portanto, resguardam relações com a qualidade ambiental. Para atender a essa demanda, os selos ambientais ou rotulagem ambiental, configuram práticas muito recentes à realidade brasileira e a terminologia adotada para caracterizá-los é vasta. Passamos a indicar alguns dos termos de rotulagem que estão sendo empregados, são eles: Ecorótulos ou ecorrótulos, Rótulo ambiental, Rótulo ecológico, Selo verde, Eco-selos, Etiqueta ecológica, ecoetiquetas, Selo ambiental, dentre outros.

Todavia, não se chegam a uma definição única a ser dada aos selos, nota-se que a utilização desses selos está numa crescente e, de certa forma, são dispositivos que podem contribuir na tomada de decisão e implementação de missão e políticas empresariais, assim como, serem definidores na hora da escolha da compra dos produtos pelos clientes. Quanto a essa temática, a Revista Vida Simples-09/2008 apontou que já são mais de 30 certificadoras "verdes" existentes no Brasil. Com referência à matéria publicada na revista citada acima, apresentamos no Quadro 9, a seguir, alguns selos ambientais do mercado adotados por certificadoras terceirizadas.

O Quadro 1 apresentado tem o intento de ilustrar ao leitor alguns dos vários selos existentes e expor um pouco sobre seus objetivos. Todavia, não se pode afirmar que todos os selos existentes foram apresentados, mesmo porque até o término desse trabalho, muitos outros selos deverão surgir no mercado.

\section{Referências}

1. Layrargues, P.P. Educação para a gestão ambiental: a cidadania no enfrentamento político dos conflitos socioambientais. In: Loureiro, C.F.B. (Org.). Sociedade e meio ambiente: a educação ambiental em debate. São Paulo: Cortez, 2000, p.85-155.

\section{Wilson de Paula e Silva}

E-mail: wsilva.senai@sistemafieg.org.br

Quadro 1. Selos ambientais amplamente aceitos pelo mercado
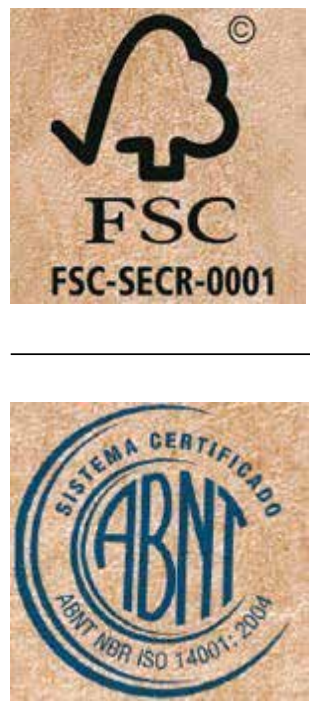

FSC (Forest Stewardship Council)

O que certifica: áreas e produtos florestais, como toras de madeira, móveis, lenha, papel, nozes e sementes.

Comoé: atesta que o produto vem de um processo produtivo ecologicamente adequado, socialmente justo e economicamente viável. Dez princípios devem ser atendidos, entre eles a obediência às leis ambientais, o respeito aos direitos dos povos indígenas e a regularização fundiária.

Outro selo dessa categoria: Ceflor

\section{ISO 14001}

O que certifica: sistema de gestão ambiental de empresas e empreendimentos de qualquer setor. Como é: em sua operação, a empresa deve levar em conta o uso racional de recursos naturais, a proteção de florestas e a preservação da biodiversidade, entre outros quesitos. No Brasil, quem confere essa certificação é a Associação Brasileira de Normas Técnicas (ABNT). Ao contrário das demais certificações, não há um selo visível em produtos. Para saber se uma empresa tem o ISO 14001, deve-se consultar seu site ou centro de atendimento ao cliente. 
Quadro 1. Selos ambientais amplamente aceitos pelo mercado - CONTINUAÇÃO.

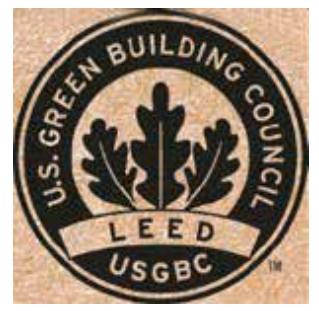

\section{LEED (Liderança em Energia e Design Ambiental)}

O que certifica: prédios e outras edificações.

Como é: concedido a edificações que minimizam impactos ambientais tanto na fase de construção quanto na de uso. Materiais renováveis, implantação de sistemas que economizem energia elétrica, água e gás e controle da poluição durante a construção são alguns dos critérios.

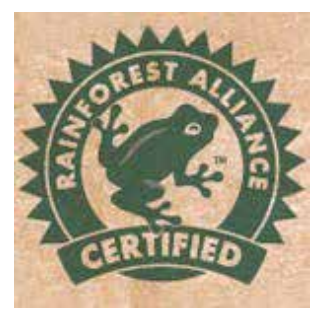

\section{Rainforest Alliance Certified}

O que certifica: produtos agrícolas, como frutas, café, cacau e chás.

Como é: trata-se de uma certificação socioambiental. Comprova que os produtores respeitam a biodiversidade e os trabalhadores rurais envolvidos no processo. Com grande aceitação na Europa e nos EUA, é auditado no Brasil pelo Instituto de Manejo e Certificação Florestal e Agrícola (Imaflora).

Outros selos dessa categoria: UTZ Kapeh e Max Havelaar.

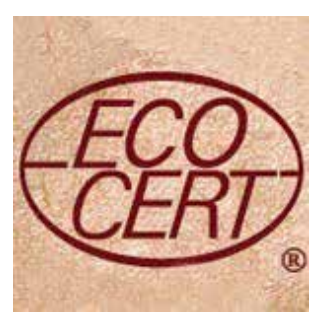

\section{ECOCERT}

O que certifica: alimentos orgânicos e cosméticos naturais ou orgânicos.

Como é: os alimentos processados devem conter um mínimo de $95 \%$ de ingredientes orgânicos para serem certificados. Para ganhar um selo de cosmético orgânico, um produto deve ter, ao menos, $95 \%$ de ingredientes vegetais e $95 \%$ destes ingredientes devem ser orgânicos certificados - no caso de cosméticos naturais, $50 \%$ dos insumos vegetais devem ser orgânicos. O selo Ecocert é um só (este ao lado). Mas, por contrato com a certificadora, o fabricante é obrigado a identificar no rótulo se o produto é orgânico ou natural.

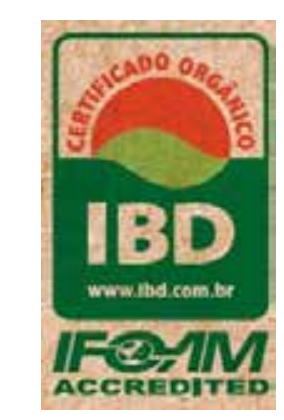

\section{IBD (Instituto Biodinâmico)}

O que certifica: alimentos, cosméticos e algodão orgânicos.

Como é: além de cumprir os requisitos básicos para a produção orgânica (como fazer rotação de culturas e não usar agrotóxicos), garante que a fabricação daquele produto obedeça ao Código Florestal Brasileiro e às leis trabalhistas. Os produtos industrializados devem ter, ao menos, $95 \%$ de ingredientes orgânicos certificados - a água e o sal são desconsiderados nesse cálculo tanto para cosméticos quanto para alimentos.

Outros selos dessa categoria: Ecocert, Demeter, CMO (Certificadora Mokiti Okada) e IMO (Institute for Marketecology).

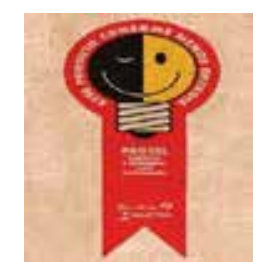

\section{Procel}

O que certifica: equipamentos eletrônicos e eletrodomésticos.

Como é: o selo do Programa Nacional de Conservação de Energia Elétrica indica os produtos que apresentam os melhores níveis de eficiência energética dentro de cada categoria. Os equipamentos passam por rigorosos testes feitos em laboratórios credenciados no programa. 
Quadro 1. Selos ambientais amplamente aceitos pelo mercado - CONTINUAÇÃO.

\section{FSC - Conselho Brasileiro de Manejo Florestal}

Certifica as áreas e produtos demanejo florestal. Existem, no Brasil, cinco certificadoras credenciadas pelo FSC. São, pelo menos, 10 critérios básicos para a obtenção, entre eles, manutenção das florestas edireitos das comunidades tradicionais e/ou rurais.

\section{FSC}

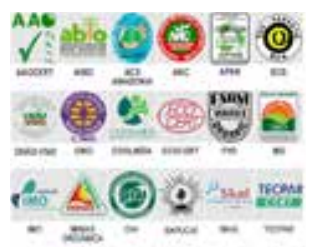

\section{IBD - Instituto Biodinâmica}

Certifica alimentos de origem orgânica. Na verdade, são dez selos diferentes que têm objetivos e finalidades diferentes. Desde o selo Demeter, originário da Alemanha, até o Ecosocial, que analisa o comprometimento social na produção.

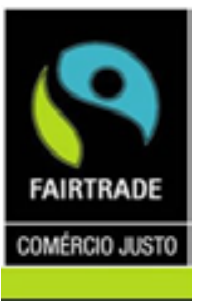

As certificadoras orientam os produtores interessados para que tomem conhecimento das "normas" de produção orgânica. Seus inspetores visitam regularmente as propriedades agrícolas, verificando o cumprimento dessas normas e se constatarem que elas foram realmente cumpridas, autorizam aos produtores que utilizem na embalagem do seu produto o "selo de qualidade" da certificadora. A única certeza do consumidor são os selos das certificadoras, cujos inspetores de fato, acompanharam todo o processo produtivo daquela banana, alface, palmito, cacau, açúcar, café, geléia etc.

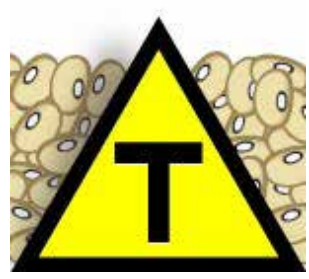

\section{Fairtrade}

É o selo do comércio justo. O respeito ao meio ambiente faz parte dos valores, mas a principal intenção desse selo é criar uma relação justa, solidária e sem atravessadores entre os pequenos produtores. Cria um sistema de comodities para produtos orgânicos ou não, desenvolvidos por pequenos proprietários.

\section{Os selos de advertência}

Além dos selos, digamos, "positivos", existe uma série de determinações para avisar o consumidor do perigo ou suposto dano que esse produto pode causar. É o caso da obrigatoriedade de avisar se o produto tem glúten ou é transgênico, por exemplo. Esse último, aliás, só agora começa a ser adotado, após muita pressão, pelas empresas. 